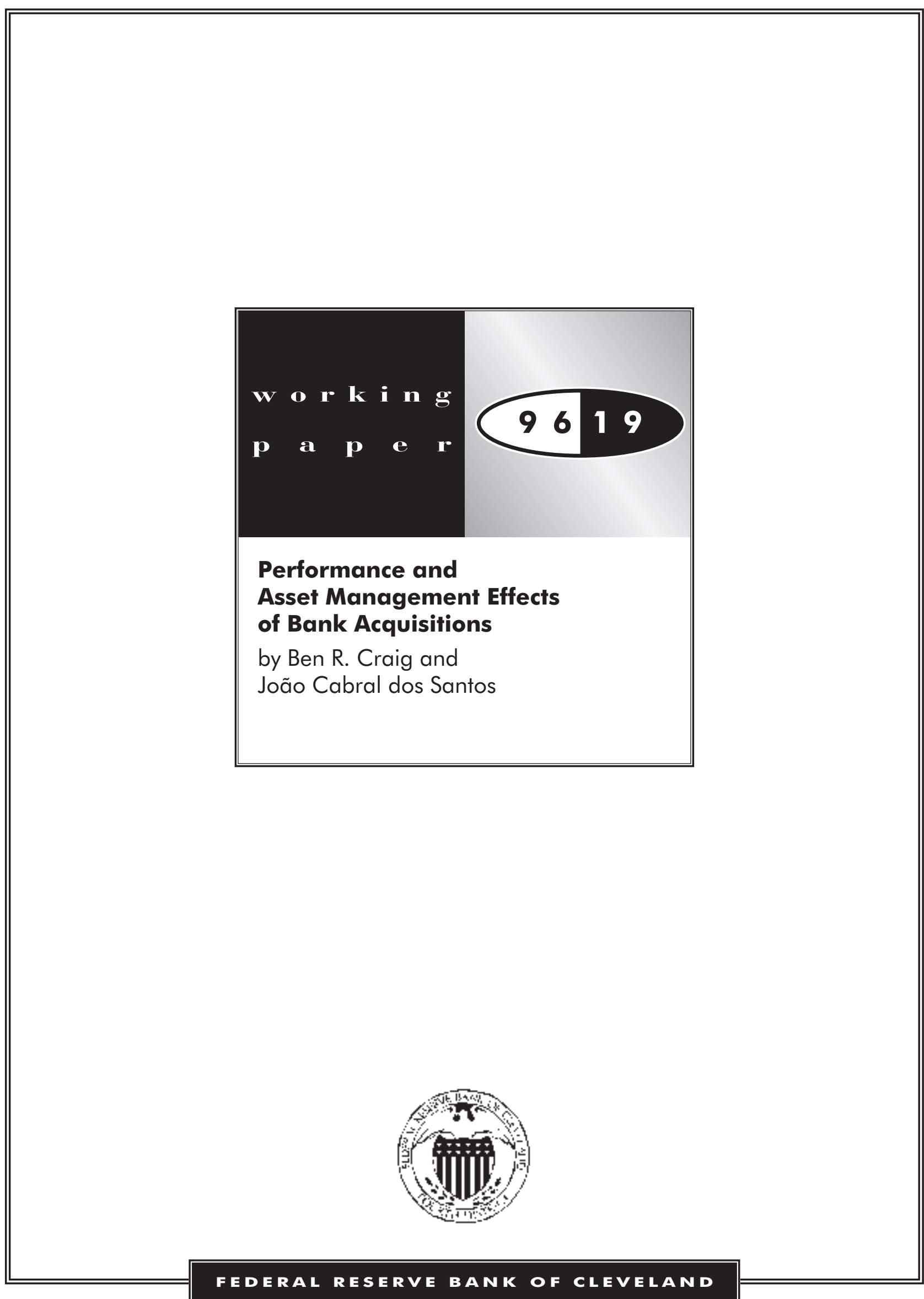


Working Paper 9619

\section{PERFORMANCE AND ASSET MANAGEMENT EFFECTS OF BANK ACQUISITIONS}

by Ben R. Craig and

João Cabral dos Santos

João Cabral dos Santos is an economist at the Federal Reserve Bank of Cleveland. The author thanks James Thomson and Joseph Haubrich for useful comments and suggestions.

Working papers of the Federal Reserve Bank of Cleveland are preliminary materials circulated to stimulate discussion and critical comment. The views stated herein are those of the authors and are not necessarily those of the Federal Reserve Bank of Cleveland or of the Board of Governors of the Federal Reserve System.

Federal Reserve Bank of Cleveland working papers are distributed for the purpose of promoting discussion of research in progress. These papers may not have been subject to the formal editorial review accorded official Federal Reserve Bank of Cleveland publications.

Working papers are now available electronically through the Cleveland Fed's home page on the World Wide Web: http://www.clev.frb.org.

May 1997 


\begin{abstract}
This paper studies the effects of acquisitions on both acquired and acquiring banks. Through the use of overlap, von Mises, and other distance statistics, we confirm that, prior to acquisition, the acquirer generally performs better than the bank it acquired. Following the acquisition, the performance of the two banks starts to converge, mainly due to improvements in the acquired institution. During this process, the acquired is transformed in such a way that it becomes a replica of its acquirer, a result that confirms a strong policy integration among banks that are part of a bank holding company. These post-acquisition effects hint at an explanation for the abnormal returns usually observed at the time of the acquisition announcement, and provide some insight on the dominant motivations for the consolidation taking place in the banking industry.
\end{abstract}




\section{Introduction}

Since the beginning of the 1980s, the banking industry in the United States has been characterized by a strong consolidation, made possible in part by the deregulation of outof-state bank acquisitions. ${ }^{1}$ Between 1960 and 1980, there were 3,592 bank mergers and acquisitions. Over the 1981-1994 period, that figure shot up to 6,157 (Rhoades [1985, 1996]). A consolidation of this magnitude certainly brings changes that are worth investigating on their own merit. It also provides valuable information about the changes we can expect to observe in the banking industry as a result of the new wave of mergers and acquisitions spawned by the Interstate Banking and Branching Efficiency Act in $1994 .^{2}$

Previous research shows that investors perceive mergers or acquisitions to be beneficial to the acquired bank; that is, there are significant positive abnormal returns for shareholders of that bank in the period surrounding the acquisition announcement. ${ }^{3}$ The same result has been found for interstate mergers (Trifts and Scanlon [1987], Cossio, Trifts, and Scanlon [1987], and Cornett and De [1991]) and for intrastate mergers (Cossio et al.). Previous studies also show that investors' perception of the acquisition effect on the acquiring bank is less clear. ${ }^{4}$ For example, based on samples of interstate mergers, Cornet and De (1991) find positive abnormal returns, Trifts and Scanlon (1987) and Cossio et al. find no significant effects, while Baradwaj, Dubofsky, and Fraser (1991) find negative abnormal returns. Mixed

\footnotetext{
${ }^{1}$ Savage (1993) describes the main features of state regulations governing out-of-state bank acquisitions. In this introduction, the terms merger and acquisition are used interchangeably. Our study, however, reports results only for bank acquisitions.

${ }^{2}$ That Act defined nationwide standards for a bank holding company (BHC) to acquire a bank in any state, implying that state laws on out-of-state acquisitions no longer apply. Furthermore, beginning June 1, 1997, BHCs will be allowed to convert their bank subsidiaries into one single network of branches, provided that the home states of these banks do not opt out of the Act's branching provision.

${ }^{3}$ Identical results are found for nonfinancial mergers. For a review of the literature on nonfinancial mergers, see Jensen and Ruback (1983) and Jarrell, Brickley, and Netter (1988).

${ }^{4}$ The literature on nonfinancial mergers finds that the acquiring firm experiences either negative or statistically insignificant abnormal returns in the period surrounding the merger announcement.
} 
results are also found for samples of intrastate mergers. Desai and Stover (1985) find positive abnormal returns, Cossio et al. find no significant effect on returns, and Baradwaj et al. find negative abnormal returns.

The literature that identifies investors' perceived benefits from merger announcements is generally mute about the source of these benefits. Is the bank's increase in value due to an expected increase in efficiency originating, for example, from economies of scale, economies of scope, or managerial X-efficiencies? ${ }^{5}$ Is it due to an expected increase in market power, or to a perceived increase in the deposit insurance subsidy? ${ }^{6}$ These questions remain largely unanswered. One strand of the literature attempts to address them through indirect evidence. Within this strand, some researchers use information available for the whole banking system on the importance of certain factors. This is particularly true regarding economies of scale, scope, and X-efficiencies. Others use the purchase premium's determinants to identify motivations for the merger, then extrapolate what might have been the source of such gains. Another strand of the literature addresses these questions in a more direct way by studying the post-merger effects. This is the avenue we follow here.

Our study, however, differs from the existing literature in several important ways. These include the method and statistics used to identify the post-merger effects, consideration of the acquiring bank's features to explain the detected changes in the acquired bank, and study of the post-merger dynamics associated with the short-term effects. In addition, we use more recent data - acquisitions occurring in the 1980s and early 1990s-which fall into a regulatory framework closer to that existing today. In particular, our study addresses the following four questions: First, to what extent do acquiring banks influence their acquired counterparts? Does this influence imply a performance and asset management convergence between them? Second, what are the short-term dynamics of the convergence? Third,

\footnotetext{
${ }^{5}$ For surveys of the literature on these issues, see Clark (1988) and Berger, Hunter, and Timme (1993).

${ }^{6}$ Banks can increase their deposit insurance subsidy by increasing their risk or, as Boyd and Graham (1991) and others suggest, by getting larger in an attempt to be considered "too big to fail."
} 
which institution (acquired or acquiring bank) contributes the most to such a convergence. And finally, does the degree of convergence depend on the characteristics of the institutions involved in the acquisition?

The study of these issues is important for a number of reasons. First, we are able to shed light on the source of the bank's increase in value at the time of the acquisition announcement. Second, we provide some insight into the dominant motivations for the acquisition. ${ }^{7}$ For example, if we see no discernible effect of the acquisition on the behavior of either the acquiring or the acquired bank, then we might attribute the abnormally high returns to a pure signaling effect of the acquisition announcement, perhaps due to information known only to the acquirer. On the other hand, if we see the asset composition of the acquired bank changing in a way that makes it more like its acquirer, and if these changes also impose a strong convergence in the performance measures of both banks, then we might conjecture that economies of scale and $\mathrm{X}$-efficiencies, rather than risk diversification, are the main motives for the acquisition. Third, we are able to show the degree of policy integration among banks that belong to a BHC. Fourth, we illustrate some of the implications of the immense consolidation taking place in the banking industry. Finally, by studying the short-term dynamics of the acquisition effects, we can provide some indication of the changes that are likely to occur in the banking sector as a result of the ongoing wave of mergers.

The paper proceeds as follows: In the next section, we present a brief review of the related literature. Section 3 describes our method and the construction of our sample, and section 4 presents our results. The paper concludes with some final observations.

\section{Related Literature}

Most of the literature studying post-merger effects concentrates on acquired banks rather than on the acquirers or the newly formed banking organizations. A frequent procedure

\footnotetext{
${ }^{7}$ Hunter and Wall (1989) survey the literature on the motivations for bank mergers.
} 
used to identify the effects on an acquired bank has been to compare, for a single variable, the difference between that bank and a similar independent bank both prior to and after the acquisition. Lawrence (1967), Tailey (1971), Ware (1973), and Hobson, Masten, and Severiens (1978) are examples of works that adopt this procedure. They examine the impact on acquired banks regarding various performance measures, including bank capital, profitability, expenses, and prices of services. ${ }^{8}$ A common finding of these early studies is that acquired banks tend to adjust their portfolio compositions by switching out of U.S. government securities and into loans and state local government securities. There is no strong evidence of acquisition effects on the profitability of these banks. The impact on their capital, expenses, and prices of services is mixed.

This way of identifying the acquisition effects on banks raises some questions. ${ }^{9}$ How similar are the acquired bank and its associated independent bank? Do these control banks behave independently from acquired banks even though they operate in the same market and the same region? Further, the samples used in some of the early studies do not permit consistent comparisons across time. Lawrence (1967) and Tailey (1971), for example, use samples in which the post-acquisition period is not equal for all the acquired banks. Ware (1973) addresses this issue by studying the impact on acquired banks one, two, and three years after the acquisition. But, because he does not keep his sample constant during that interval, the results among those three years are not strictly comparable. Hobson, Masten, and Severiens (1978) correct this problem by studying a sample of banks acquired in 1969 over the 1969-1975 period. However, the use of a sample of acquisitions occurring in a single year might exhibit results that are peculiar to that year.

Rhoades (1986) employs a different procedure - multiple regression analysis - to study

\footnotetext{
${ }^{8}$ Rose (1987) uses a univariate analysis to compare the post-merger performance of acquiring banks with that of independent banks.

${ }^{9}$ For a detailed discussion of these questions and a survey of the research on post-merger effects, see Frieder and Apilado (1982) and Rhoades (1986).
} 
the effect of an acquisition on acquired banks' profitability, operating expenses, and market share. He finds no significant impact on these variables for the acquired banks, a conclusion that mirrors the results found in the univariate analysis literature. ${ }^{10}$

Cornett and Tehranian (1992) focus on how an acquisition impacts the performance of the newly formed banking organization: the acquirer and the acquired bank. Using mean annual return on assets (before taxes), they find that the new banking organization underperforms the industry in the three years prior to acquisition, but outperforms the industry in the three years following the acquisition. Furthermore, the difference between these averages is significantly different from zero, confirming an increase in the performance of banking organizations after acquisition. The authors find identical results for their subsamples of interstate and intrastate acquisitions, and they also show that the difference in the increase for each subsample's return on assets is not significantly different from zero, indicating that the performance improvement is identical for interstate and intrastate acquisitions.

Most of the studies mentioned above evaluate the post-acquisition effects for samples of bank acquisitions that occurred in a regulatory framework substantially different from that existing today, particularly regarding conditions on intrastate branching. ${ }^{11}$ In addition, they do not evaluate the post-acquisition effects on the new banking organization (other than its profitability), nor do they attempt to explain the changes observed in the acquired banks using the characteristics of their acquirers. Yet the study of these issues is essential to understanding how a BHC is managed, to grasping both the motivation behind bank acquisitions and the source of the increase in the bank's value at the time of the acquisition announcement, and to evaluating the impact of such acquisitions on the configuration of

\footnotetext{
${ }^{10}$ Mingo (1975) and Mayne (1977) also use a multivariate analysis, but their objective is to compare the performance of acquired banks with that of independent banks in the years preceding and following the acquisition.

${ }^{11}$ During the 1970 s and the early 1980 s, many states had restrictions on intrastate branching, and others even required unit banking.
} 
the banking sector - a particularly timely issue given the ongoing wave of mergers and acquisitions.

\section{Method and Sample Construction}

To address the issues mentioned above, we compute, for different variables, a statistic that directly compares the acquired and the acquiring bank both before and after the acquisition. This procedure allows us to study the acquisition effects on the newly formed banking organization and to connect the acquisition effects observed on the acquired bank to its acquirer, rather than focusing exclusively on the acquired bank's changes. Moreover, to study the short-run dynamics of the acquisition effects, we compute such statistics over time with a constant sample of acquisitions. That is, for a given time frame defined around the acquisition date, we consider only those acquisitions for which we have observations throughout the entire period. Thus, we avoid the problems of a changing sample composition and of having a sample of acquisitions made in a single period.

\subsection{Distance Measures}

We adopt a two-step procedure. In the first step, we compute a statistic comparing the acquiring and the acquired bank at each point in time. In the second step, we measure the acquisition effect by comparing that statistic before and after the acquisition. In the first step, our comparison statistic can always be interpreted as a distance between measures of the acquiring and the acquired bank. In most cases, this is straightforward. For example, if the performance variable is the ratio of net income after taxes to equity capital, then the measure of comparison is just the simple distance between two scalars, or the absolute value of the difference between them. Thus, when we compare two scalars, such as the return on equity or the return on assets, we define a distance measure between the acquiring bank $i$ 
and the $j$ th bank acquired by $i$, when measured at time $t$, to be

$$
D_{i, j, t}=\left|X_{i, t}-X_{j, t}\right|
$$

where $X_{i, t}$ is the criterion variable at time $t$ for the acquiring bank, and $X_{j, t}$ is the same variable for the acquired bank.

The situation changes when we attempt to identify the acquisition effects in the composition of a portfolio rather than in a scalar. This happens, for example, when we measure the acquisition effects on the composition of the bank's portfolio of securities or loans. For this purpose, we use two measures of distance popular in the statistics literature: the overlap statistic, which measures the area of non-intersection of the two distributions, and the von Mises statistic, which measures the distance between the distributions in the $l_{2}$ norm. More formally, if $P_{i, t, g}$ is the percentage of assets held by acquiring bank $i$ in security category $g$ at time $t$, and $P_{j, t, g}$ is the same percentage for the $j$ th bank (acquired by bank $i$ ), then the overlap statistic is

$$
O_{i, j, t}=\sum_{g=1}^{M}\left|P_{i, t, g}-P_{j, t, g}\right|
$$

and the von Mises statistic is

$$
V_{i, j, t}=\left\{\sum_{g=1}^{M}\left(P_{i, t, g}-P_{j, t, g}\right)^{2}\right\}^{\frac{1}{2}} .
$$

The two distance measures range from 0 , if the portfolio compositions are identical, to 2 , if they are completely disjoint.

In the second step, we identify the acquisition effects by comparing the distance measures at two different points in time, one before and one after the acquisition. We assume that the distance measures are stochastic, with an error structure of the form:

$$
Y_{i, j, t}=\beta_{t}+e_{i, j}+e_{i, j, t}
$$

where $Y \in\{D, O, V\}, e_{i, j}$ is a component of the error that is peculiar to the pair of acquiring and acquired banks $i$ and $j, e_{i, j, t}$ is a random error with an expectation of zero, and $\beta_{t}$ is 
a parameter measuring the true distance as a function of time. A consistent estimate of the convergence measure computed $t$ periods after the acquisition, when compared with $s$ periods before the acquisition, $\beta_{t}-\beta_{s}$, is the sample mean of the statistic

$$
\delta Y_{s, t}=\frac{\sum_{i, j}\left(Y_{i, j, t}-Y_{i, j, s}\right)}{N},
$$

where $N$ is the total number of relevant acquisitions. If this statistic is significantly negative, then the distance between the banks is decreasing, indicating that acquired and acquiring banks are growing more alike. Because this is a measure of the difference in distance, the more negative $\delta Y_{s, t}$ is, the more the banks are converging. Similarly, if $\delta_{s, t}$ is positive, then the banks are diverging along this performance or behavior measure. In addition, by looking at the change in $\delta Y_{s, t}$ for a given value of $s$, as $t$ increases, we gain insight into the dynamics of the convergence.

Although $D_{i, j, t}, O_{i, j, t}$, and $V_{i, j, t}$ are distance measures, they are bounded. For example, if the performance measure is a scalar, such as a proportion, then $D_{i, j, t} \in[0,1]$ and the corresponding comparison measure, $\delta D_{s, t}, \in[-1,1]$. The overlap and the von Mises distances are in the interval $[0,2]$. Their corresponding comparison measures, $\delta O_{s, t}$ and $\delta V_{s, t}$, respectively, have the relevant range $[-2,2]$.

The statistics presented above tell us whether there was any convergence between the acquired bank and the acquiring bank following the acquisition. They also convey information about the magnitude of such phenomena. However, they do not identify the party that contributed the most to such convergence. In order to identify this party, we follow a different two-step procedure. In the first step, we compute for each party (the acquired and the acquiring bank) the changes that occur during the period extending from $s$ quarters before the acquisition to $t$ quarters after it. In the second step, we compare these changes in order to identify which party was affected most by the acquisition. Thus, if $X$ is the variable being studied, then we compute the following two distance measures: $I_{i, s, t}=\left|X_{i, t}-X_{i, s}\right|$ and $I_{j, s, t}=\left|X_{j, t}-X_{j, s}\right|$. These measure the magnitude of the variation in $X$ for the ac- 
quiring bank $i$ and its $j$ th acquired bank, for the period extending from $s$ quarters before to $t$ quarters after the acquisition. In the second step, we compute the difference in this distance, that is,

$$
\delta I_{s, t}=\frac{\sum_{i, j}\left(I_{i, s, t}-I_{j, s, t}\right)}{N} .
$$

We can identify the party where the largest change in $X$ occurred by looking at the sign of the statistic $\delta I_{s, t}$. When $\delta I_{s, t}=0$, either neither party changed between quarters $s$ and $t$, or they both changed by the same amount. When the acquired bank changed $X$ by more than the acquiring bank, $\delta I_{s, t}<0$. The opposite is meant when $\delta I_{s, t}>0$.

\subsection{Variable Definitions}

As mentioned before, we attempt to identify the acquisition effects on both the performance and the asset management of banks. ${ }^{12}$ The traditional measures of performance are the ratio of net income to equity capital (return on equity) and the ratio of net income to total assets (return on assets.) We decompose the return-on-assets variable to better understand which component contributes the most to any trend we might observe in this performance variable. Thus, we also look at total interest income, total interest expense, non-interest income, and non-interest expense, all as ratios to total assets.

In order to assess the acquisition effects on a bank's asset composition, we study the changes in the composition of three portfolios. The first is the bank's portfolio of securities. Based on Call Report data, we are able to identify seven categories of securities, such as U.S. Treasury securities, securities issued by states, and foreign debt securities. As a result, the bank's portfolio of securities is defined by the shares of its investment in securities that are associated with each of the seven categories. ${ }^{13}$ The second portfolio includes the bank's loans and leases. Here, the composition of the portfolio is given by the shares of

\footnotetext{
${ }^{12}$ The definitions presented here are based on Call Report terminology.

${ }^{13} \mathrm{By}$ construction, the sum of these seven shares is one.
} 
the bank's loans and leases that are associated with different activities or institutions, such as construction and development, depository institutions, and commercial and industrial firms. We identify 15 different categories of loans. The third portfolio includes the entire composition of the bank's portfolio of assets. In this case, the composition of the portfolio is given by the percentages of the bank's total assets held in each category of individual assets. In addition to the seven categories of securities and the 15 types of loans, we are able to identify 10 more different assets associated with cash accounts, intangible assets, and "other" fixed assets.

Finally, we complement the study of the acquisition effects on banks' asset compositions through the use of several traditional measures, including the simple percentage of total assets held in securities, the percentage of total assets held in loans and leases, and two frequently used measures of bank leverage: the ratio of equity capital to total assets and the ratio of equity capital to loans and leases.

\subsection{Time Frames and Sample}

For each given "time frame," we define a sample of bank acquisitions that is kept "constant." By time frame, we mean an interval of time with a set number of quarters before and a set number of quarters after the acquisition date. By constant sample, we mean a sample of acquisitions, each satisfying two criteria: availability of data for both parties involved in the acquisition throughout the entire time frame, and constancy of the structure of the parties involved (that is, they made no further acquisitions or sales throughout the time frame). For example, if the time frame is chosen to be from four quarters before the acquisition to 16 quarters after it, then an acquisition is considered in this time frame only if we have data for both the acquired and the acquiring bank, which includes one year prior to the acquisition and four years after it, and if during that period the aquiring bank does not make any other acquisitions or sales of banks. 
Note that the longer the time frame adopted, the more important the restriction imposed by the requirement that the sample of acquisitions stays constant within the time frame. Because of this, in addition to the time frame that includes four quarters before the acquisition and 16 quarters after it, we also investigate shorter time frames, defined by four quarters before and four, eight, and 12 quarters after the acquisition. In all cases, our results are robust, so we report only the results for the most restrictive sample, that is, the sample that stays constant from four quarters before the acquisition until 16 quarters after it, which we denote the 4 -by-16 time frame.

The fact that our results are insensitive to the duration of the time frame is reassuring in one important sense. Because the 4-by-16 time frame represents a five-year period, the results could in principle be generated by an attrition bias; that is, paired observations that managed to survive the five-year period could have been such a special subgroup that conclusions drawn from them may not hold up for the more general population. However, our results were not affected when we performed the tests for the different samples associated with very short time frames, indicating that the attrition bias can have at most a small effect on our results.

Based on the procedure described above, the treatment of BHCs that make only one acquisition during our sample period (from the first quarter of 1984 to the last quarter of 1993) is straightforward. With respect to the BHCs that make more than one acquisition during that period, we adopt the following rule: Suppose the BHC makes a second acquisition $t$ quarters after the first acquisition. If $t \geq 16$, the first acquisition is considered in the samples of all four time frames. If $12 \leq t<16$, that acquisition is excluded from the 4 -by-16 time frame sample, but is included in the other three samples. The same logic is applied for the cases where $8 \leq t<12$ and $4 \leq t<8$. The second acquisition is then considered for each of the time frames in the same way as for the single-acquisition case, provided that it occurs at least four quarters after the acquisition. The same procedure is adopted if there is a 
third and fourth acquisition.

As mentioned before, our study reports results only for bank acquisitions, not for bank mergers. Further, we restrict our sample of bank acquisitions to acquisitions of independent banks made by one-tier BHCs, that is, BHCs that own banks but do not own other BHCs. Once the samples of bank acquisitions associated with each time frame have been defined, the distance statistics are computed in accordance with the following procedure. In the case of a single acquisition made by a BHC that owns only one bank, we use the values of the acquired bank and the acquiring BHC. If there is a second acquisition made by that BHC, the distances are computed using the values of the acquired bank and the weighted average of the two banks in the acquiring BHC. The same rule applies when acquisitions are made by multibank BHCs. ${ }^{14}$

\subsection{Data}

The data for this study are taken from Call Reports submitted between the first quarter of 1984 and the last quarter of 1993. To obtain both pre- and post-acquisition information, we consider only those acquisitions that occurred between the third quarter of 1984 and the first quarter of 1993.

We define a multistate $\mathrm{BHC}$ to be a company that owns banks in more than one state at the end of our sample period. This might have been the result of acquisitions made during the sample period or of the BHC already owning banks in more than one state at the beginning of 1984. Otherwise, the BHC is defined as a single-state entity. Our sample of banks' acquisitions is summarized in table 1 . There were 64 acquisitions made by multistate BHCs and 400 acquisitions made by single-state BHCs. Note that in both cases, a substantial number of acquisitions (25 and 189, respectively) were made by BHCs

\footnotetext{
${ }^{14}$ The weights are the denominators of the ratios being considered.
} 
that had one bank and acquired only a second bank during the sample period.

\begin{tabular}{|c|c|c|c|c|c|c|c|c|c|c|c|}
\hline & & \multicolumn{10}{|c|}{ Number of banks in the BHCs after the latest acquisition } \\
\hline & & 2 & 3 & 4 & 5 & 6 & 7 & $\cdots$ & 10 & $\ldots$ & 13 \\
\hline \multirow{9}{*}{$\begin{array}{l}\text { Number of } \\
\text { banks in } \\
\text { the BHCs } \\
\text { before } \\
\text { the first } \\
\text { acquisition }\end{array}$} & & \multicolumn{10}{|c|}{ Number of multistate BHCs in the sample } \\
\hline & 1 & 25 & 5 & 4 & 3 & 1 & - & $\cdots$ & - & $\cdots$ & - \\
\hline & & \multicolumn{10}{|c|}{ Number of single-state BHCs in the sample } \\
\hline & 1 & 189 & 41 & 13 & 4 & 3 & 1 & $\cdots$ & - & $\cdots$ & - \\
\hline & 2 & - & 13 & 5 & - & 2 & - & $\cdots$ & - & $\cdots$ & 1 \\
\hline & 3 & - & - & 2 & - & - & - & $\ldots$ & - & $\ldots$ & - \\
\hline & 4 & - & - & - & - & 1 & 1 & $\ldots$ & - & $\ldots$ & - \\
\hline & 5 & - & - & - & - & - & - & $\ldots$ & - & $\ldots$ & - \\
\hline & 6 & - & - & - & - & - & - & $\ldots$ & 1 & $\ldots$ & - \\
\hline
\end{tabular}

Table 2 contains some descriptive statistics on the ratio of the acquired bank's assets to the assets of the largest bank in the acquiring BHC given the number of banks in the acquiring $\mathrm{BHC}$.

\begin{tabular}{|c|c|c|c|c|c|c|c|c|c|c|c|c|}
\hline \multicolumn{13}{|c|}{$\begin{array}{l}\text { Table 2: Ratio of Acquired Bank's Assets to the Assets of the } \\
\text { Largest Bank in the Acquiring BHC }\end{array}$} \\
\hline & \multicolumn{12}{|c|}{ Number of banks in the acquiring BHC } \\
\hline & 1 & 2 & 3 & 4 & 5 & 6 & 7 & 8 & 9 & 10 & 11 & 12 \\
\hline & \multicolumn{12}{|c|}{ Acquisitions by multistate BHCs } \\
\hline $\mathrm{N}^{a}$ & 37 & 13 & 8 & 4 & 1 & - & - & - & - & - & - & - \\
\hline Mean & 0.40 & 0.29 & 0.32 & 0.24 & 0.18 & - & - & - & - & - & - & - \\
\hline Median & 0.24 & 0.18 & 0.21 & 0.21 & 0.18 & - & - & - & - & - & - & - \\
\hline $\mathrm{CV}^{b}$ & 0.92 & 0.92 & 0.83 & 1.17 & - & - & - & - & - & - & - & - \\
\hline \multicolumn{13}{|c|}{ Acquisitions by single-state BHCs } \\
\hline $\mathrm{N}^{a}$ & 277 & 88 & 34 & 14 & 10 & 4 & 2 & 2 & 2 & 1 & 1 & 1 \\
\hline Mean & 0.58 & 0.55 & 0.59 & 0.86 & 0.37 & 0.26 & 0.08 & 0.10 & 0.08 & 0.06 & 0.17 & 0.08 \\
\hline Median & 0.48 & 0.45 & 0.42 & 0.31 & 0.32 & 0.21 & 0.08 & 0.10 & 0.08 & 0.06 & 0.17 & 0.08 \\
\hline $\mathrm{CV}^{b}$ & 0.87 & 0.82 & 1.05 & 2.19 & 0.67 & 0.66 & 0.47 & 0.49 & 0.30 & - & - & - \\
\hline
\end{tabular}

${ }^{a}$ Number of acquiring BHCs.

${ }^{b}$ Coefficient of variation. 
Based on table 2, we see that, for example, in 88 observations of our sample, single-state BHCs with two banks acquired a third bank, and, on average, the assets of the acquired banks were 55 percent of the assets of the largest bank in the two-bank acquiring BHC. Two features of the sample are made clear in table 2: Acquired banks, on average, are substantially smaller than acquiring banks, and this difference is larger for the acquisitions made by multistate BHCs than for those made by single-state BHCs.

To conduct some additional tests, we further decompose the samples of bank acquisitions made by single-state and multistate BHCs in the following way: Subsample SS1 includes the acquisitions made by single-state BHCs that had one bank at the beginning of the sample period and made only one acquisition during the entire period. Subsample SS2 contains all the acquisitions made by single-state BHCs. It includes SS1 plus all the other cases, such as the acquisitions made by BHCs that had more than one bank at the beginning of the sample period, and the cases where the acquiring BHC made more than one acquisition during the sample period. Subsamples MS1 and MS2 are defined in the same way, but include acquisitions made by multistate BHCs. The number of acquisitions in each subsample is presented in table 3 .

This separation allows us to test whether the acquisition effects depend on the geographic characteristics of the acquiring BHC (single-state versus multistate company) and on the structure of the acquiring BHC (a company that initially owns only one bank and makes only one acquisition during our sample period, versus all the other cases).

\begin{tabular}{|l|cccc|}
\hline \multicolumn{1}{|c|}{ Table 3: Number of } & Acquisitions in each & Time & Frame \\
\hline \hline & 4 by 4 & 4 by 8 & 4 by 12 & 4 by 16 \\
\hline SS1 & 165 & 144 & 127 & 113 \\
SS2 & 288 & 227 & 192 & 168 \\
\hline MS1 & 22 & 18 & 15 & 11 \\
MS2 & 46 & 32 & 27 & 20 \\
\hline TS $^{a}$ & 334 & 259 & 219 & 188 \\
\hline
\end{tabular}

${ }^{a}$ TS represents our total sample of acquisitions. 


\section{Results}

We find that acquisitions have clear and robust effects on a bank's performance and asset management, regardless of the time frame and the subsample adopted. ${ }^{15}$ First, there are significant changes in both the asset management measures and the performance measures following the acquisition. The former begin immediately in the quarter after the acquisition, while the performance effects become more pronounced one year following the acquisition. Second, such changes systematically indicate a convergence between the acquiring BHC and the acquired banks following the acquisition. We find that this convergence increases with time; that is, the longer the period of time following the acquisition, the more alike the acquired and acquiring banks become. Furthermore, we find no evidence of convergence prior to the acquisition. Third, we find that these patterns hold regardless of the size of the institutions involved in the acquisition, and regardless of whether the acquirer is a single-state or a multistate BHC. Finally, we detect clear evidence that most of the changes behind the convergence occur in the acquired banks, that is, acquirers dictate acquired banks' policies and force them to become similar to the acquirers.

\subsection{The Post-Acquisition Effects on Asset Management}

We identify the acquisition effects on the composition of banks' portfolios of securities, loans, and total assets through overlap and von Mises statistics. Table A.1 presents the results for the effects on the overlap and von Mises statistics for the 4-by-16 time frame.

The first pair of lines in each block of the table contain the information associated with the overlap statistic. The first line represents the average difference of the overlap statistic $t$ quarters after the acquisition minus the same statistic four quarters before, that is, $\delta O_{-4, t}$.

\footnotetext{
${ }^{15}$ The results for the total sample and for the SS subsamples tend to be more significant than those for the MS subsamples. This is particularly true for MS1, because of the small number of observations associated with this subsample.
} 
For each point in time, the overlap statistic is computed between the acquiring BHC and the acquired bank. The second line represents the $p$-value for the null hypothesis that the difference is zero over time. The $p$-value is calculated using the standard $t$-distribution. For example, with respect to the first block (composition of the securities portfolio), the entry under 12 quarters after acquisition indicates that the overlap statistic between the two banks was on average smaller at that time (0.1580) than it was four quarters before the acquisition. The hypothesis that this number is zero has a $p$-value of $2.3210^{-6}$, which means that no difference between the two distances would be rejected at any reasonable significance level. Clearly, the banks are moving closer together when measured by the overlap distance on the composition of the securities portfolio. The second pair of lines in each block contains the same information for the von Mises statistic.

There are some clear patterns in table A.1. First, the overlap statistic and the von Mises statistic give virtually the same results. Second, acquisition always causes the two parties to converge in their asset management, that is, the portfolio compositions of securities, loans and leases, and total assets become more alike after the acquisition. All of the entries in table A.1 are negative, and all are statistically significant, with the exception of the first quarter in securities. Second, the convergence increases with time. The absolute value of $\delta O_{s, t}$ and $\delta V_{s, t}$ always increases with $t$, indicating that the acquiring and the acquired bank grow more and more alike with time. Third, the convergence process is still ongoing 16 quarters after the acquisition. Finally, the convergence in the portfolio of securities starts later in the sample period than that of the portfolio of loans and leases.

Table A.2 presents the results for both the statistic $\delta D_{s, t}$, which measures convergence, and the statistic $\delta I_{s, t}$, which measures the relative contribution of each bank to the convergence. These results are reported for the set of scalar variables, which include equity capital as a fraction of loans and leases and as a fraction of total assets, and the proportions of the bank's total assets in securities and in loans and leases. The results from $\delta D_{s, t}$ show the 
same patterns as the overlap and von Mises statistics. Along all of these measures, banks are converging, convergence increases with time, and the convergence is statistically significant. Note, though, that the convergence in the securities-to-assets and in the loans-to-assets ratios is stronger than the convergence observed in the equity capital-to-assets ratio.

The results from $\delta I_{s, t}$ measure which bank is more responsible for the convergence, the acquiring or the acquired. Clearly, the measures are all statistically significant and negative, indicating that the acquired bank changes its behavior in response to acquisition, becoming more like the acquiring bank. Further, this is true throughout the process of convergence. When the acquired bank ceases changing from its pre-acquisition status, the process of convergence stops.

The fact that we use four quarters before the acquisition as a benchmark raises the question of whether the results would be different had we used a different quarter. The relevance of the quarter chosen prior to the acquisition depends on whether any convergence occurs before the acquisition takes place. To address this issue, we use the procedure described above, but compare the statistics of the fourth quarter before the acquisition with the statistics of each quarter until the quarter of the acquisition. Tables A.3 and A.4 contain this information for the variables found in tables A.1 and A.2, respectively. The results show no evidence of convergence prior to the acquisition. Thus, the post-acquisition results are not affected by the choice of the pre-acquisition benchmark quarter.

The results presented above are robust with respect to both the variable being studied and the nature of the acquiring bank. We find identical results based on our subsamples of acquisitions made by single-state and multistate BHCs (SS2 and MS2, respectively). We also find identical results based on our subsamples of acquirers that have one bank and make only one acquisition during the sample period (SS1 and MS1, respectively) for single-state and multistate acquiring BHCs. ${ }^{16}$

\footnotetext{
${ }^{16}$ We also performed the same tests and obtained the same results for subsamples of acquiring BHCs that had two banks and acquired a third during our sample period.
} 
The robustness of the results also appears in our regression analysis. Table A.5 presents the regression results. These regressions follow the form

$$
\delta Y_{i, j}=\alpha_{0}+\alpha_{1} Y_{i, j}+\alpha_{2} Z_{i, j}
$$

where $Y$, a distance measure, $\in\{D, O, V\}$, and $\delta Y_{i, j}$ is computed at four quarters before and 16 quarters after the acquisition; $Y_{i, j}$ is computed at the acquisition date; and $Z_{i, j}$ is a vector of explanatory variables measured at the time of the acquisition. ${ }^{17}$ All of the regressions have the same pattern. In only one regression does total assets have a statistically significant effect: on the return to equity. In all the other regressions, total assets of either the acquiring $\mathrm{BHC}$ or the acquired bank do not affect the convergence process when considered separately or in sum. Similarly, whether the acquisition is made by a single-state or multistate BHC has no effect. The only clear result from the regressions is that banks which initially were far apart displayed more convergence. In other words, if their initial positions at the time of acquisition are more distant $\left(Y_{i, j}\right.$ is larger), then they converge significantly more.

\subsection{The Post-Acquisition Effects on Performance}

The performance of both the acquired and acquiring banks relative to the industry is reported in table B.1. The entries measure the difference between the banks or BHCs' return and the average return for the banking industry as a whole for a given quarter. Thus, the number 0.01298 for the acquiring banks' return on equity (net income divided by equity capital) at eight quarters after the acquisition date (quarter 0) indicates that these banks have a return on equity that is, on average, 1.3 percent higher than the industry average at the same time. The second entry, $2 \times 10^{-8}$, is the $p$-value for the null hypothesis that the expected value of the acquiring banks' rate of return is the same as that of the industry as

\footnotetext{
${ }^{17}$ We also ran regressions where $\delta Y_{i, j}$ was measured at many post-acquisition quarters other than 16 , and with the explanatory variables measured at four quarters before the acquisition. None of these changes altered our results.
} 
a whole. Clearly, acquiring banks outperform the industry average at any reasonable significance level eight periods after the acquisition. These tests are computed for the acquiring and the acquired banks, and for the new banking organization formed as a result of the acquisition, that is, for the aggregate of the acquiring and the acquired banks (before the acquisition date, this represents a fictional aggregate banking organization).

The patterns for the acquiring bank and the banking organization formed as a result of the acquisition are the same. This is not surprising, since the acquiring banks are in general substantially larger than the acquired banks (see table 1). Acquiring banks' returns to equity and to assets are larger than for the industry as a whole over the entire period. However, the excess returns taper off somewhat, starting in the tenth quarter after the acquisition date. Acquired banks show a less clear pattern. Before acquisition, they generally underperform the industry, although the difference usually is not statistically significant. After acquisition, acquired banks outperform the industry briefly in the second and third year, but otherwise perform about equally well. These patterns are consistent with some of the existing literature, which shows an increase in the performance of acquired banks following acquisition.

We also look at the relative performance of the acquiring and acquired banks. In light of the strong convergence observed in the portfolio composition, which increases with time, it is natural to expect the same pattern in the convergence of performance between these banks. Furthermore, given that acquired banks contribute more to the convergence in the assets portfolio, we should also expect them to contribute more to the convergence in performance. The first two panels of table B.2 report the results for the return on equity and the return on assets. They strongly confirm our expectations.

At this point, a natural question is, what is the major component contributing to the convergence in the banks' profitability? From the bottom two panels of table B.2, it is apparent that the convergence comes equally from interest and non-interest income. To 
further evaluate this issue, we decompose these two items into their revenue and expense sides. The results are reported in table B.3. Total non-interest income is the only component that does not display convergence between the acquiring and the acquired bank. Note, however, that regarding the other three components (total interest income, total interest expense, and total non-interest expense), non-interest expense is the only component for which we clearly observe the acquired bank making the major contribution to convergence, an indication that this bank is the main contributor to the consolidation in back-office operations and in the branch network that develops following the acquisition.

\section{Final Remarks}

As mentioned in the introduction, previous research on bank mergers and acquisitions shows that investors perceive the merger or acquisition to be beneficial to the acquired bank; that is, there are significant positive abnormal returns for shareholders of that bank in the period surrounding the acquisition announcement. The effects on the acquiring bank's stock price tend to be fuzzier. What are the sources of these expected gains?

Our results confirm that acquiring banks generally perform better than the banks they acquire in the period prior to acquisition. Furthermore, we show that once the acquisition takes place, the performance of these banks starts converging, mainly because of improvements in the acquired bank (particularly the reduction in its non-interest expenses). In this process, the acquired bank is transformed along a wide variety of dimensions - including the compositions of its portfolios of securities, loans, and total assets - such that it becomes a replica of the acquirer. These post-acquisition results show a greater degree of policy integration among banks belonging to a BHC than do previous research findings. For example, Lawrence (1971, p. 52) concludes: "Certain bank investments, specifically securities investments and federal funds transactions ... are generally closely controlled by the holding company or the lead bank. On the other hand, pricing policies, decisions on the composition 
of the loan portfolio, and decisions with respect to individual loan applications are usually made by the individual banks."

The post-acquisition patterns unveiled here provide some information on both the motive for the acquisition and the increase in the acquired bank's value at the time of the acquisition announcement. These patterns clearly indicate that no special or strategic role is attributed to the acquired bank after the acquisition. They also seem to downplay the importance of one of the most frequently suggested motivations for bank mergers and acquisitions: risk reduction. Had this been the case, we would not observe the replication effect developing in such a pronounced way. Further, our findings also appear to downplay the market-power motive. If this were the main reason for the acquisitions, acquirers would attempt to avoid the adjustment costs associated with the acquired bank's changes by choosing more appropriate targets. Such post-acquisition effects seem to provide more support for the $\mathrm{X}$-efficiencies and economies of scale motives instead.

Finally, our results appear to indicate that the source of the increase in the acquired bank's value at the time of the acquisition announcement is essentially the expectation that policies which made the acquirers more profitable and successful will be applied to them. As a way to test this hypothesis, it would seem useful to merge, for the same sample of acquisitions, our approach to identifying the post-acquisition effects with an analysis of the determinants of the abnormal returns associated with the acquisition announcement. In particular, what is the explanatory power of the differences in performance and asset composition between the acquired and the acquiring bank at the time of the acquisition? If our interpretation of the acquired bank's abnormal returns is correct, then we should observe a positive correlation between these returns and the difference in performance and asset composition between the acquirer and the acquired bank at the time of the acquisition. 


\section{Appendix A: Post-Acquisition Effects on Assets}

\begin{tabular}{|c|c|c|c|c|c|c|c|c|}
\hline & \multicolumn{8}{|c|}{ Quarters After the Acquisition } \\
\hline & 1 & 2 & 3 & 4 & 6 & 8 & 12 & 16 \\
\hline \multirow{5}{*}{$\begin{array}{l}\delta O_{-4, t} \\
p \\
\delta V_{-4, t} \\
p\end{array}$} & \multicolumn{8}{|c|}{ Securities Composition } \\
\hline & -0.0254 & -0.0461 & -0.0392 & -0.0890 & -0.0905 & -0.1030 & -0.1580 & -0.1830 \\
\hline & 0.18900 & 0.04080 & 0.10300 & 0.00182 & 0.00213 & 0.00039 & $2.32 \mathrm{e}-06$ & $3.13 \mathrm{e}-07$ \\
\hline & -0.0186 & -0.0403 & -0.0331 & -0.0680 & -0.0676 & -0.0788 & -0.1020 & -0.1100 \\
\hline & 0.18800 & 0.01290 & 0.06050 & 0.00040 & 0.00037 & $3.25 \mathrm{e}-05$ & $7.75 \mathrm{e}-07$ & $7.02 \mathrm{e}-07$ \\
\hline \multirow{5}{*}{$\begin{array}{l}\delta O_{-4, t} \\
p \\
\delta V_{-4, t} \\
p\end{array}$} & \multicolumn{8}{|c|}{ Loans and Leases Composition } \\
\hline & -0.0399 & -0.0482 & -0.0573 & -0.0766 & -0.0863 & -0.0989 & -0.1000 & -0.1240 \\
\hline & 0.00111 & 0.00029 & $7.31 \mathrm{e}-05$ & $5.40 \mathrm{e}-07$ & $3.21 \mathrm{e}-07$ & $1.41 \mathrm{e}-07$ & $1.26 \mathrm{e}-07$ & $4.32 \mathrm{e}-09$ \\
\hline & -0.0101 & -0.0143 & -0.0184 & -0.0236 & -0.0249 & -0.0281 & -0.0289 & -0.0355 \\
\hline & 0.01120 & 0.00158 & 0.00015 & $1.67 \mathrm{e}-06$ & $3.21 \mathrm{e}-06$ & $2.09 \mathrm{e}-06$ & $4.28 \mathrm{e}-06$ & $3.87 \mathrm{e}-07$ \\
\hline \multirow{5}{*}{$\begin{array}{l}\delta O_{-4, t} \\
p \\
\delta V_{-4, t} \\
p\end{array}$} & \multicolumn{8}{|c|}{ Total Assets Composition } \\
\hline & -0.0283 & -0.0465 & -0.0552 & -0.0794 & -0.1040 & -0.1160 & -0.1400 & -0.1490 \\
\hline & 0.01410 & 0.00031 & $4.30 \mathrm{e}-05$ & $1.29 \mathrm{e}-07$ & $9.31 \mathrm{e}-10$ & $6.88 \mathrm{e}-11$ & $9.93 \mathrm{e}-14$ & $1.43 \mathrm{e}-14$ \\
\hline & -0.0067 & -0.0114 & -0.0130 & -0.0172 & -0.0230 & -0.0265 & -0.0318 & -0.0305 \\
\hline & 0.05470 & 0.00502 & 0.00146 & $9.46 \mathrm{e}-05$ & $8.11 \mathrm{e}-07$ & $5.62 \mathrm{e}-08$ & $1.41 \mathrm{e}-10$ & $3.05 \mathrm{e}-10$ \\
\hline
\end{tabular}




\begin{tabular}{|c|c|c|c|c|c|c|c|c|}
\hline \multirow{7}{*}{$\begin{array}{l}\delta D_{-4, t} \\
p \\
\delta I_{-4, t} \\
p\end{array}$} & \multicolumn{8}{|c|}{ Quarters After the Acquisition } \\
\hline & 1 & 2 & 3 & 4 & 6 & 8 & 12 & 16 \\
\hline & \multicolumn{8}{|c|}{ Securities to Total Assets Ratio } \\
\hline & -0.0136 & -0.0153 & -0.0173 & -0.0236 & -0.0306 & -0.0363 & -0.0398 & -0.0325 \\
\hline & 0.00983 & 0.00722 & 0.00262 & 0.00026 & $7.24 \mathrm{e}-06$ & $1.54 \mathrm{e}-07$ & $3.55 \mathrm{e}-07$ & $4.82 \mathrm{e}-05$ \\
\hline & -0.0198 & -0.0179 & -0.0168 & -0.0191 & -0.0236 & -0.0265 & -0.0323 & -0.0266 \\
\hline & $1.98 \mathrm{e}-05$ & 0.00024 & 0.00078 & 0.00082 & 0.00018 & $7.76 \mathrm{e}-05$ & $2.83 \mathrm{e}-05$ & 0.00017 \\
\hline \multirow{5}{*}{$\begin{array}{l}\delta D_{-4, t} \\
p \\
\delta I_{-4, t} \\
p\end{array}$} & \multicolumn{8}{|c|}{ Loans and Leases to Total Assets Ratio } \\
\hline & -0.0096 & -0.0122 & -0.0134 & -0.0181 & -0.0246 & -0.0311 & -0.0421 & -0.0394 \\
\hline & 0.05560 & 0.02790 & 0.02350 & 0.00450 & 0.00046 & $5.64 \mathrm{e}-05$ & $1.96 \mathrm{e}-07$ & $1.41 \mathrm{e}-06$ \\
\hline & -0.0145 & -0.0170 & -0.0207 & -0.0254 & -0.0260 & -0.0368 & -0.0424 & -0.0396 \\
\hline & 0.00126 & 0.00115 & $3.52 \mathrm{e}-05$ & $5.26 \mathrm{e}-06$ & 0.00013 & $7.22 \mathrm{e}-07$ & $3.76 \mathrm{e}-08$ & $2.05 \mathrm{e}-06$ \\
\hline \multirow{5}{*}{$\begin{array}{l}\delta D_{-4, t} \\
p \\
\delta I_{-4, t} \\
p\end{array}$} & \multicolumn{8}{|c|}{ Equity Capital to Total Assets Ratio } \\
\hline & -0.0043 & -0.0049 & -0.0062 & -0.0071 & -0.0077 & -0.0087 & -0.0086 & -0.0106 \\
\hline & 0.00952 & 0.00511 & 0.00076 & $8.16 \mathrm{e}-05$ & $3.30 \mathrm{e}-05$ & $4.10 \mathrm{e}-06$ & $4.44 \mathrm{e}-06$ & $1.60 \mathrm{e}-07$ \\
\hline & -0.0095 & -0.0097 & -0.0101 & -0.0097 & -0.0093 & -0.0087 & -0.0084 & -0.0082 \\
\hline & $1.47 \mathrm{e}-08$ & 7.63e-08 & $4.97 \mathrm{e}-08$ & $4.09 \mathrm{e}-08$ & $2.88 \mathrm{e}-07$ & $6.95 \mathrm{e}-07$ & $3.60 \mathrm{e}-06$ & $2.85 \mathrm{e}-05$ \\
\hline \multirow{5}{*}{$\begin{array}{l}\delta D_{-4, t} \\
p \\
\delta I_{-4, t} \\
p\end{array}$} & \multicolumn{8}{|c|}{ Equity Capital to Loans and Leases Ratio } \\
\hline & -0.0199 & -0.0239 & -0.0295 & -0.0346 & -0.0405 & -0.0437 & -0.0459 & -0.0462 \\
\hline & 0.01370 & 0.00296 & 0.00044 & 0.00011 & $1.19 \mathrm{e}-05$ & $3.70 \mathrm{e}-06$ & $2.46 \mathrm{e}-06$ & $5.85 \mathrm{e}-06$ \\
\hline & -0.0248 & -0.0230 & -0.0291 & -0.0333 & -0.0341 & -0.0399 & -0.0419 & -0.0451 \\
\hline & 0.00136 & 0.00267 & 0.00036 & $7.18 \mathrm{e}-05$ & $8.13 \mathrm{e}-05$ & $9.00 \mathrm{e}-06$ & $9.83 \mathrm{e}-06$ & $8.05 \mathrm{e}-06$ \\
\hline
\end{tabular}




\begin{tabular}{|c|c|c|c|c|}
\hline & \multicolumn{4}{|c|}{ Quarters Before the Acquisition } \\
\hline & -3 & -2 & -1 & 0 \\
\hline & \multicolumn{4}{|c|}{ Securities Composition } \\
\hline$\delta O_{-4, t}$ & 0.0035 & -0.0088 & -0.0130 & -0.0166 \\
\hline$p$ & 0.58300 & 0.35200 & 0.28100 & 0.25000 \\
\hline$\delta V_{-4, t}$ & 0.0002 & 0.0032 & -0.0067 & -0.0089 \\
\hline \multirow[t]{2}{*}{$p$} & 0.50800 & 0.57700 & 0.31700 & 0.30900 \\
\hline & \multicolumn{4}{|c|}{ Loans and Leases Composition } \\
\hline$\delta O_{-4, t}$ & -0.0015 & -0.0008 & -0.0050 & -0.0313 \\
\hline$p$ & 0.40300 & 0.46100 & 0.30500 & 0.00465 \\
\hline$\delta V_{-4, t}$ & 0.0005 & -0.0023 & -0.0010 & -0.0082 \\
\hline \multirow[t]{2}{*}{$p$} & 0.59300 & 0.20100 & 0.40300 & 0.01980 \\
\hline & \multicolumn{4}{|c|}{ Total Assets Composition } \\
\hline$\delta O_{-4, t}$ & -0.0027 & 0.0015 & -0.0075 & -0.0195 \\
\hline$p$ & 0.34900 & 0.56400 & 0.24300 & 0.06110 \\
\hline$\delta V_{-4, t}$ & -0.0003 & -0.0001 & -0.0002 & -0.0042 \\
\hline$p$ & 0.42300 & 0.48200 & 0.47900 & 0.15700 \\
\hline
\end{tabular}




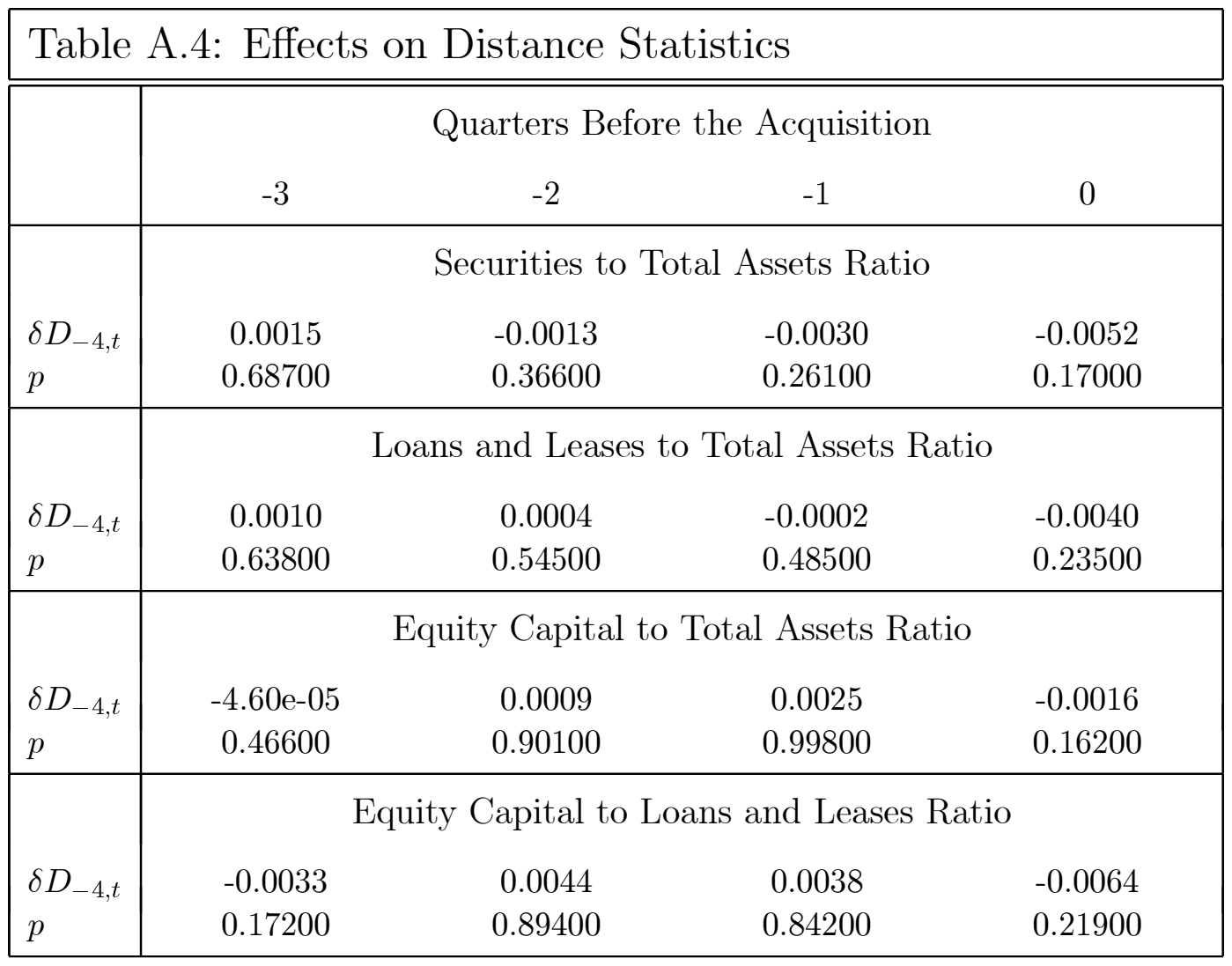




\begin{tabular}{|c|c|c|c|c|c|c|}
\hline \multirow{2}{*}{$\begin{array}{l}\text { Dependent Variables } \\
\delta O_{-4,16} \text { for: }\end{array}$} & \multicolumn{5}{|c|}{ Independent Variables $^{b}$} & \multirow[t]{2}{*}{$R^{2}$} \\
\hline & $C^{t e}$ & $\begin{array}{l}\text { Multistate } \\
\text { Dummy }\end{array}$ & $O$ & $\begin{array}{r}\text { Total A } \\
\text { Acquiring }\end{array}$ & $\begin{array}{l}\text { sets of: } \\
\text { Acquired }\end{array}$ & \\
\hline Securities Composition & $\begin{array}{c}0.3873 \\
(8.39)\end{array}$ & $\begin{array}{l}0.0057 \\
(0.07)\end{array}$ & $\begin{array}{l}-0.8797 \\
(-14.50)\end{array}$ & $\begin{array}{c}-2.44 \mathrm{e}-08 \\
(-0.63)\end{array}$ & $\begin{array}{c}6.85 \mathrm{e}-08 \\
(0.41)\end{array}$ & 0.55 \\
\hline Loans Composition & $\begin{array}{c}0.3461 \\
(7.39)\end{array}$ & $\begin{array}{c}-0.0760 \\
(-1.38)\end{array}$ & $\begin{array}{l}-0.7008 \\
(-10.86)\end{array}$ & $\begin{array}{c}6.06 \mathrm{e}-08 \\
(2.36)\end{array}$ & $\begin{array}{c}-1.13 \mathrm{e}-07 \\
(-1.01)\end{array}$ & 0.41 \\
\hline Assets Composition & $\begin{array}{r}0.3567 \\
(7.54)\end{array}$ & $\begin{array}{c}-0.0211 \\
(-0.45)\end{array}$ & $\begin{array}{l}-0.7102 \\
(-11.50)\end{array}$ & $\begin{array}{c}3.35 \mathrm{e}-08 \\
(1.52)\end{array}$ & $\begin{array}{c}7.41 \mathrm{e}-08 \\
(0.77)\end{array}$ & 0.44 \\
\hline$\delta D_{-4,16}$ for the ratio of: & \multicolumn{5}{|c|}{$D$} & \\
\hline Capital to Assets & $\begin{array}{c}0.1963 \\
(8.69)\end{array}$ & $\begin{array}{c}0.0509 \\
(1.18)\end{array}$ & $\begin{array}{l}-0.6585 \\
(-10.19)\end{array}$ & $\begin{array}{c}9.50 \mathrm{e}-09 \\
(0.47)\end{array}$ & $\begin{array}{c}8.56 \mathrm{e}-08 \\
(0.98)\end{array}$ & 0.37 \\
\hline Capital to Loans & $\begin{array}{c}0.0387 \\
(3.50)\end{array}$ & $\begin{array}{c}-0.0065 \\
(-0.23)\end{array}$ & $\begin{array}{l}-0.5312 \\
(-10.29)\end{array}$ & $\begin{array}{c}-2.73 \mathrm{e}-09 \\
(-0.21)\end{array}$ & $\begin{array}{c}3.05 \mathrm{e}-08 \\
(0.54)\end{array}$ & 0.38 \\
\hline Securities to Assets & $\begin{array}{c}0.0075 \\
(18.58)\end{array}$ & $\begin{array}{c}0.0005 \\
(1.14)\end{array}$ & $\begin{array}{l}-0.8533 \\
(-19.68)\end{array}$ & $\begin{array}{c}-1.93 \mathrm{e}-10 \\
(-1.01)\end{array}$ & $\begin{array}{c}-3.15 \mathrm{e}-09 \\
(-3.76)\end{array}$ & 0.69 \\
\hline Loans to Assets & $\begin{array}{c}0.0094 \\
(6.15)\end{array}$ & $\begin{array}{c}0.0026 \\
(1.45)\end{array}$ & $\begin{array}{c}-0.6688 \\
(-7.36)\end{array}$ & $\begin{array}{c}-1.96 \mathrm{e}-10 \\
(-0.24)\end{array}$ & $\begin{array}{c}1.57 \mathrm{e}-09 \\
(0.44)\end{array}$ & 0.25 \\
\hline Net Inc. to Capital & $\begin{array}{c}0.0104 \\
(8.42)\end{array}$ & $\begin{array}{c}0.0003 \\
(0.33)\end{array}$ & $\begin{array}{l}-0.6000 \\
(-10.83)\end{array}$ & $\begin{array}{c}-1.69 \mathrm{e}-09 \\
(-3.70)\end{array}$ & $\begin{array}{c}-4.17 \mathrm{e}-10 \\
(-0.21)\end{array}$ & 0.43 \\
\hline Net Inc. to Assets & $\begin{array}{l}0.0288 \\
(10.00)\end{array}$ & $\begin{array}{c}0.0006 \\
(0.15)\end{array}$ & $\begin{array}{l}-0.9030 \\
(-12.59)\end{array}$ & $\begin{array}{c}-3.13 \mathrm{e}-09 \\
(-1.57)\end{array}$ & $\begin{array}{c}-1.32 \mathrm{e}-09 \\
(-0.15)\end{array}$ & 0.48 \\
\hline Int. Inc. to Assets & $\begin{array}{c}0.0046 \\
(7.55)\end{array}$ & $\begin{array}{c}0.0001 \\
(0.16)\end{array}$ & $\begin{array}{c}-0.7494 \\
(-7.45)\end{array}$ & $\begin{array}{c}-1.25 \mathrm{e}-10 \\
(-0.45)\end{array}$ & $\begin{array}{c}-1.81 \mathrm{e}-09 \\
(-1.46)\end{array}$ & 0.24 \\
\hline Int. Exp. to Assets & $\begin{array}{c}0.0869 \\
(3.84)\end{array}$ & $\begin{array}{c}-0.0008 \\
(-0.03)\end{array}$ & $\begin{array}{c}-0.2978 \\
(-4.84)\end{array}$ & $\begin{array}{c}-7.48 \mathrm{e}-09 \\
(-0.62)\end{array}$ & $\begin{array}{c}-2.15 \mathrm{e}-08 \\
(-0.41)\end{array}$ & 0.12 \\
\hline Non-int. Inc. to Assets & $\begin{array}{c}0.1451 \\
(6.13)\end{array}$ & $\begin{array}{c}0.0058 \\
(0.25)\end{array}$ & $\begin{array}{c}-0.2434 \\
(-4.68)\end{array}$ & $\begin{array}{c}-5.73 \mathrm{e}-10 \\
(-0.05)\end{array}$ & $\begin{array}{c}-5.62 \mathrm{e}-08 \\
(-1.19)\end{array}$ & 0.12 \\
\hline Non-int. Exp. to Assets & $\begin{array}{c}0.0340 \\
(7.61)\end{array}$ & $\begin{array}{c}-0.0044 \\
(-0.37)\end{array}$ & $\begin{array}{l}-0.9135 \\
(-18.91)\end{array}$ & $\begin{array}{c}-4.94 \mathrm{e}-09 \\
(-0.90)\end{array}$ & $\begin{array}{c}5.25 \mathrm{e}-09 \\
(0.22)\end{array}$ & 0.68 \\
\hline
\end{tabular}

${ }^{a} \mathrm{t}$ values are in parentheses.

${ }^{b}$ Independent variables are measured at four periods prior to the acquisition. 


\section{Appendix B: Post-Acquisition Effects on Performance}

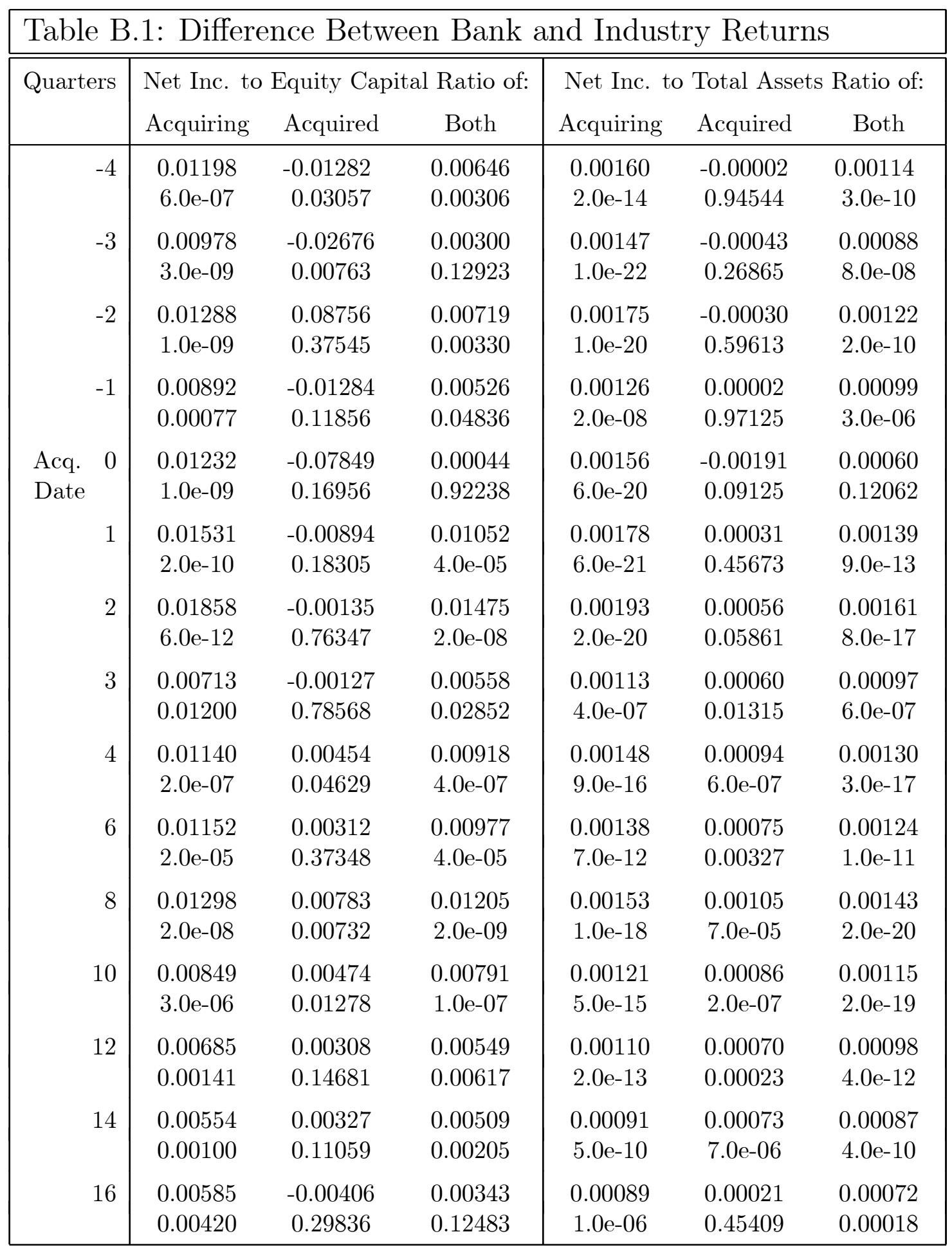




\begin{tabular}{|c|c|c|c|c|c|c|c|c|}
\hline \multirow{7}{*}{$\begin{array}{l}\delta D_{-4, t} \\
p \\
\delta I_{-4, t} \\
p\end{array}$} & \multicolumn{8}{|c|}{ Quarters After the Acquisition } \\
\hline & 1 & 2 & 3 & 4 & 6 & 8 & 12 & 16 \\
\hline & \multicolumn{8}{|c|}{ Net Income to Equity Capital Ratio } \\
\hline & -0.0026 & -0.0110 & -0.0143 & -0.0216 & -0.0179 & -0.0233 & -0.0250 & -0.0206 \\
\hline & 0.36700 & 0.02680 & 0.01860 & 0.00015 & 0.00160 & $1.81 \mathrm{e}-05$ & $6.01 \mathrm{e}-06$ & 0.00062 \\
\hline & -0.0395 & -0.0274 & -0.0259 & -0.0253 & -0.0277 & -0.0206 & -0.0229 & -0.0255 \\
\hline & $1.01 \mathrm{e}-07$ & $1.83 \mathrm{e}-06$ & 0.00013 & 8.67-06 & $2.70 \mathrm{e}-06$ & 0.00019 & $5.68 \mathrm{e}-05$ & $2.37 \mathrm{e}-05$ \\
\hline \multirow{5}{*}{$\begin{array}{l}\delta D_{-4, t} \\
p \\
\delta I_{-4, t} \\
p\end{array}$} & \multicolumn{8}{|c|}{ Net Income to Total Assets Ratio } \\
\hline & -0.0003 & -0.0007 & -0.0011 & -0.0014 & -0.0012 & -0.0016 & -0.0018 & -0.0015 \\
\hline & 0.27800 & 0.02620 & 0.00186 & 0.00014 & 0.00116 & $2.26 \mathrm{e}-05$ & $2.55 \mathrm{e}-07$ & $4.40 \mathrm{e}-05$ \\
\hline & -0.0024 & -0.0016 & -0.0013 & -0.0015 & -0.0018 & -0.0014 & -0.0014 & -0.0015 \\
\hline & $3.91 \mathrm{e}-09$ & $3.37 \mathrm{e}-06$ & 0.00041 & $1.07 \mathrm{e}-05$ & $1.74 \mathrm{e}-06$ & $8.23 \mathrm{e}-05$ & $5.27 \mathrm{e}-05$ & $4.75 \mathrm{e}-05$ \\
\hline \multirow{5}{*}{$\begin{array}{l}\delta D_{-4, t} \\
p \\
\delta I_{-4, t} \\
p\end{array}$} & \multicolumn{8}{|c|}{ Net Interest Income to Total Assets Ratio } \\
\hline & -0.0004 & -0.0005 & -0.0004 & -0.0006 & -0.0008 & -0.0009 & -0.0012 & -0.0012 \\
\hline & 0.01330 & 0.00083 & 0.02730 & 0.00066 & $1.78 \mathrm{e}-05$ & $1.02 \mathrm{e}-06$ & $2.15 \mathrm{e}-09$ & $1.30 \mathrm{e}-09$ \\
\hline & -0.0006 & -0.0004 & -0.0007 & -0.0006 & -0.0006 & -0.0007 & -0.0007 & -0.0006 \\
\hline & 0.00027 & 0.00333 & 0.00031 & 0.00022 & 0.00034 & 0.00013 & $8.83 \mathrm{e}-05$ & 0.00226 \\
\hline \multirow{5}{*}{$\begin{array}{l}\delta D_{-4, t} \\
p \\
\delta I_{-4, t} \\
p\end{array}$} & \multicolumn{8}{|c|}{ Net Non-interest Income to Total Assest Ratio } \\
\hline & -0.0004 & -0.0004 & -0.0003 & -0.0006 & -0.0008 & -0.0008 & -0.0008 & -0.0007 \\
\hline & 0.00761 & 0.00782 & 0.15200 & 0.00025 & $3.48 \mathrm{e}-05$ & $1.18 \mathrm{e}-05$ & $6.38 \mathrm{e}-05$ & 0.00128 \\
\hline & -0.0006 & -0.0008 & -0.0008 & -0.0006 & -0.0006 & -0.0008 & -0.0006 & -0.0009 \\
\hline & 0.00012 & $7.32 \mathrm{e}-07$ & 0.00015 & $8.53 \mathrm{e}-05$ & 0.00014 & $2.69 \mathrm{e}-06$ & 0.00054 & $6.37 \mathrm{e}-05$ \\
\hline
\end{tabular}




\begin{tabular}{|c|c|c|c|c|c|c|c|c|}
\hline \multirow{7}{*}{$\begin{array}{l}\delta D_{-4, t} \\
p \\
\delta I_{-4, t} \\
p\end{array}$} & \multicolumn{8}{|c|}{ Quarters After the Acquisition } \\
\hline & 1 & 2 & 3 & 4 & 6 & 8 & 12 & 16 \\
\hline & \multicolumn{8}{|c|}{ Total Interest Income to Total Assets Ratio } \\
\hline & -0.0003 & -0.0006 & -0.0002 & -0.0005 & -0.0007 & -0.0009 & -0.0010 & -0.0011 \\
\hline & 0.02100 & 0.00016 & 0.22900 & 0.00443 & $1.92 \mathrm{e}-05$ & $1.52 \mathrm{e}-08$ & $1.58 \mathrm{e}-08$ & $5.53 \mathrm{e}-10$ \\
\hline & -0.0002 & -0.0002 & -0.0004 & -0.0003 & -0.0002 & -0.0003 & 0.0002 & -0.0004 \\
\hline & 0.20200 & 0.17000 & 0.07610 & 0.05820 & 0.20100 & 0.06960 & 0.15300 & 0.01950 \\
\hline \multirow{5}{*}{$\begin{array}{l}\delta D_{-4, t} \\
p \\
\delta I_{-4, t} \\
p\end{array}$} & \multicolumn{8}{|c|}{ Total Interest Expense to Total Assets Ratio } \\
\hline & -0.0002 & -0.0004 & -0.0002 & -0.0004 & -0.0006 & -0.0006 & -0.0006 & -0.0008 \\
\hline & 0.02730 & 0.00024 & 0.18600 & 0.00168 & $5.91 \mathrm{e}-06$ & $8.76 \mathrm{e}-06$ & $1.31 \mathrm{e}-06$ & $2.82 \mathrm{e}-09$ \\
\hline & $5.49 \mathrm{e}-05$ & $2.90 \mathrm{e}-05$ & -0.0001 & -0.0001 & -0.0002 & -0.0002 & -0.0003 & -0.0003 \\
\hline & 0.72300 & 0.60200 & 0.24300 & 0.14600 & 0.09210 & 0.03890 & 0.01400 & 0.02140 \\
\hline & \multicolumn{8}{|c|}{ Total Non-interest Income to Total Assets Ratio } \\
\hline$\delta D_{-4, t}$ & $-3.61 \mathrm{e}-05$ & $-9.47 \mathrm{e}-05$ & 0.0001 & -0.0002 & -0.0001 & -0.0001 & -0.0001 & $-4.35 \mathrm{e}-05$ \\
\hline$p$ & 0.40200 & 0.27600 & 0.76700 & 0.08620 & 0.19800 & 0.18100 & 0.18100 & 0.40300 \\
\hline$\delta I_{-4, t}$ & $3.28 \mathrm{e}-07$ & $-2.47-06$ & -0.0001 & $9.34 \mathrm{e}-05$ & $4.78 \mathrm{e}-05$ & $3.69 \mathrm{e}-05$ & $-1.45 \mathrm{e}-05$ & $-2.95 \mathrm{e}-05$ \\
\hline \multirow[t]{2}{*}{$p$} & 0.50100 & 0.49400 & 0.22600 & 0.72700 & 0.61600 & 0.59600 & 0.46500 & 0.43200 \\
\hline & \multicolumn{8}{|c|}{ Total Non-interest Expense to Total Assets Ratio } \\
\hline$\delta D_{-4, t}$ & -0.0004 & -0.0005 & -0.0002 & -0.0006 & -0.0007 & -0.0006 & -0.0008 & -0.0007 \\
\hline$p$ & 0.01460 & 0.00263 & 0.14900 & 0.00077 & $4.54 \mathrm{e}-05$ & 0.00048 & $5.38 \mathrm{e}-05$ & 0.00226 \\
\hline$\delta I_{-4, t}$ & -0.0006 & -0.0007 & -0.0007 & -0.0007 & -0.0006 & -0.0008 & -0.0006 & -0.0008 \\
\hline$p$ & $5.99 \mathrm{e}-05$ & $3.44 \mathrm{e}-06$ & 0.00073 & $8.96 \mathrm{e}-06$ & 0.00038 & $5.38 \mathrm{e}-06$ & 0.00025 & $3.75 \mathrm{e}-05$ \\
\hline
\end{tabular}




\section{References}

Baradwaj, B. G., D. A. Dubofsky, and D. R. Fraser (1991) "Bidder Returns in Interstate and Intrastate Bank Acquisitions," Journal of Financial Services Research 5, pp. 261-273.

Berger, A. N., W. C. Hunter, and S. G. Timme (1993) "The Efficiency of Financial Institutions: A Review and Preview of Research Past, Present, and Future," Journal of Banking and Finance 17, pp. 221-249.

Boyd, J. H., and S. L. Graham (1991) "Investigating the Bank Consolidation Trend," Federal Reserve Bank of Minneapolis, Quarterly Review, Spring, pp. 3-15.

Clark, J. A. (1988) "Economies of Scale and Scope at Depository Financial Institutions: A Review of the Literature," Federal Reserve Bank of Kansas City, Economic Review, September/October, pp. 16-33.

Cornett, M. M., and S. De (1991) "Common Stock Returns in Corporate Takeover Bids: Evidence from Interstate Bank Mergers," Journal of Banking and Finance 15, pp. $273-295$.

Cornett, M. M., and H. Tehranian (1992) "Changes in Corporate Performance Associated with Bank Acquisitions," Journal of Financial Economics 21, pp. 211-234.

Cossio, F., J. W. Trifts, and K. P. Scanlon (1987) "Bank Equity Returns: The Difference Between Intrastate and Interstate Bank Mergers," Federal Reserve Bank of Chicago, Proceedings of a Conference on Bank Structure and Competition, pp. 591-600.

Desai, A. S., and R. D. Stover (1985) "Bank Holding Company Acquisitions, Stockholder Returns, and Regulatory Uncertainty," Journal of Financial Services Research 8, pp. $145-156$.

Frieder, L. A., and V. P. Apilado (1982) "Bank Holding Company Research: Classification, Synthesis, and New Directions," Journal of Bank Research, Summer, pp. 80-95. 
Hobson, H. A., J. T. Masten, and J. T. Severiens (1978) "Holding Company Acquisitions and Bank Performance: A Comparative Study," Journal of Bank Research 9, pp. $116-120$.

Hunter, W. C., and L. D. Wall (1989) "Bank Merger Motivations: A Review of the Evidence and an Examination of Key Target Bank Characteristics," Federal Reserve Bank of Atlanta, Economic Review, September/October, pp. 2-19.

Jarrell, G., J. Brickley, and J. Netter (1988) "The Market for Corporate Control: Empirical Evidence Since 1980," Journal of Economic Perspectives 2, pp. 49-68.

Jensen, M., and R. Ruback (1983) "The Market for Corporate Control: The Scientific Evidence," Journal of Financial Economics 11, pp. 5-50.

Lawrence, R. J. (1971) "Operating Policies of Bank Holding Companies-Part I," Board of Governors of the Federal Reserve System, Staff Study No. 59.

Lawrence, R. J. (1967) "The Performance of Bank Holding Companies," Board of Governors of the Federal Reserve System, Staff Study No. 55 .

Mayne, L. S. (1977) "A Comparative Study of Bank Holding Company Affiliates and Independent Banks, 1969-1972," Journal of Finance 32, pp. 147-158.

Mingo, J. J. (1975) "Capital Management and Profitability of Prospective Holding Company Banks," Journal of Financial and Quantitative Analysis 10, pp. 191-201.

Rhoades, S. A. (1996) "Bank Mergers and Industrywide Structure, 1980-94," Board of Governors of the Federal Reserve System, Staff Study No. 160.

Rhoades, S. A. (1986) "The Operating Performance of Acquired Firms in Banking Before and After Acquisitions," Board of Governors of the Federal Reserve System, Staff Study No. 149.

Rhoades, S. A. (1985) "Mergers and Acquisitions by Commercial Banks, 1960-83," Board of Governors of the Federal Reserve System, Staff Study No. 142. 
Rose, P. S. (1987) "The Impact of Mergers in Banking: Evidence from a Nationwide Sample of Federally Chartered Banks," Journal of Economic Business 39, pp. 289-312.

Savage, D. T. (1993) "Interstate Banking: A Status Report," Federal Reserve Bulletin 79, pp. $1075-1089$.

Tailey, S. H. (1971 "The Effect of Holding Company Acquisitions on Bank Performance," Board of Governors of the Federal Reserve System, Staff Study No. 62 .

Trifts, J. W., and K. P. Scanlon (1987) "Interstate Bank Mergers: The Early Evidence," Journal of Financial Research 10, pp. 305-311.

Ware, R. F. (1973) "Performance of Banks Acquired by Multibank Holding Companies in Ohio," Federal Reserve Bank of Cleveland, Economic Review, March/April, pp. $19-28$. 